\title{
Supervisi Individual yang Kontinyu untuk Meningkatkan Kemampuan Mengelola Pembelajaran Guru Mata Pelajaran di SMAN 2 Pujut
}

\author{
Lalu Sahbin \\ SMAN 2 Pujut, Kabupaten Lombok Tengah - Provinsi NTB \\ *Corresponding Author. Email: lalusahbin@gmail.com
}

\begin{abstract}
The purpose of this research is to improve the ability to manage the learning of subject teachers through continuous individual supervision. The research method used is school action research which consists of two cycles, each cycle consisting of planning, implementation, observation and reflection stages. Data collection techniques using documentation, observation and checklists. The data analysis technique in this study used descriptive analysis. The results of this study indicate that the classroom management competence of subject teachers increases from cycle to cycle, in the pre-cycle the average value of the pedagogic competence of 15 teachers is $80 \%$. In the first cycle the number of teachers who made the syllabus and lesson plans was $33 \%$ and $27 \%$, in the second cycle there was an increase in the number of teachers' syllabus and lesson plans by $80 \%$ and $87 \%$, while the competence of teachers in compiling the syllabus and lesson plans increased to $87 \%$. Thus, through individual supervision, subject teachers can improve the ability to manage learning.
\end{abstract}

Abstrak: Tujuan penelitian ini adalah untuk meningkatkan kemampuan mengelola pembelajaran guru mata pelajaran melalui supervisi individual yang kontinyu. Metode penelitian yang digunakan adalah penelitian tindakan sekolah yang terdiri dari dua siklus, setiap siklus terdiri dari tahap perencanaan, pelaksanaan, pengamatan, refleksi. Teknik pengumpulan data menggunakan dokumentasi, observasi dan ceklist. Teknik analisis data pada penelitian ini menggunakan analisis deskriptif. Hasil penelitian ini menunjukkan bahwa kompetensi pengelolaan kelas guru mata pelajaran meningkat dari siklus ke siklus, pada pra siklus nilai rata-rata kompetensi pedagogik 15 orang guru adalah $80 \%$. Pada siklus I jumlah guru yang membuat Silabus dan RPP 33\% dan $27 \%$, pada siklus II terjadi peningkatan jumlah silabus dan RPP guru adalah $80 \%$ dan $87 \%$, sedangkan kompetensi guru dalam menyusun silabus dan RPP meningkat menjadi $87 \%$. Dengan demikian melalui supervisi individual guru mata pelajaran dapat meningkatkan kemampuan mengelola pembelajaran.

\section{Article History}

Received: 09-08-2020

Reviewed: 11-09-2021

Accepted: 26-09-2021

Published: 18-10-2021

\section{Key Words}

Ability To Manage

Learning, Individual

Supervision, Continuous.

\section{Sejarah Artikel}

Diterima: 09-08-2020

Direview: 11-09-2021

Disetujui: 26-09-2021

Diterbitkan: 18-10-2021

\section{Kata Kunci}

Kemampuan Mengelola Pembelajaran, Supervisi Individual, Kontinyu.

How to Cite: Sahbin, L. (2021). Supervisi Individual yang Kontinyu untuk Meningkatkan Kemampuan Mengelola Pembelajaran Guru Mata Pelajaran di SMAN 2 Pujut. Jurnal Teknologi Pendidikan : Jurnal Penelitian dan Pengembangan Pembelajaran, 6(2), 193-200. doi:https://doi.org/10.33394/jtp.v6i2.4262

\section{Pendahuluan}

Kemampuan mengelola pembelajaran adalah kemampuan dalam menciptakan dan mempertahankan kondisi kelas yang optimal guna terjadinya proses belajar mengajar yang serasi dan efektif (Etin Solihatin, 2013). Kemampuan dasar mengajar (teaching skills) merupakan suatu keterampilan khusus (most specific instructional behaviors) yang harus dipunyai guru untuk dapat melaksanakan tugas mengajar secara efektif, efisien dan professional (Gilcman dalam Islamuddin 2021; Supatni, 2017).

Dalam upaya meningkatkan kemampuan guru dalam melaksanakan tugas profesinya, maka peningkatan kemampuan dan kompetensi guru dapat dilakukan dengan mencakup kegiatan-kegiatan yang bertujuan untuk perbaikan dan pertumbuhan kemampuan (abilities), 
sikap (attitude), dan keterampilan (skill) harus dilakukan. Dari kegiatan ini diharapkan akan menghasilkan suatu perubahan perilaku guru yang secara nyata perubahan perilaku tersebut berdampak pada peningkatan kinerja guru dalam proses belajar mengajar di kelas (Mulyasa, 2012).

Upaya meningkatkan kemampuan guru merupakan sebagai salah satu cara untuk memenuhi standar kompetensi guru sesuai dengan tuntutan profesi dan perkembangan ilmu pengetahuan, teknologi, dan seni. Meningkatkan kemampuan guru menjadi bagian penting yang harus selalu dilakukan secara terus menerus atau yang kontinyu untuk menjaga profesionalitas guru (Majid, 2005).

Ada beberapa alasan mengapa seorang guru harus terus belajar selama dia berprofesi sebagai pendidik (Wardani, 2007; Sapari, 2002), sebagai berikut.

1) Profesi guru merupakan bidang pekerjaan khusus yang dilaksanakan berdasarkan prinsip profesionalitas memiliki kesempatan untuk mengembangkan keprofesionalan secara yang kontinyu dengan belajar sepanjang hayat.

2) Perkembangan ilmu pengetahuan, teknologi dan seni menuntut guru untuk harus belajar beradaptasi dengan hal-hal baru yang berlaku saat ini. Dalam kondisi ini, seorang guru dituntut untuk bisa beradaptasi dengan berbagai perubahan yang baru.

3) Karakter peserta didik yang senantiasa berbeda dari generasi ke generasi menjadi tantangan tersendiri bagi seorang guru. Metode pembelajaran yang digunakan pada peserta didik generasi terdahulu akan sulit diterapkan pada peserta didik generasi sekarang. Oleh karena itu, cara ataupun metode pembelajaran yang digunakan guru harus disesuaikan dengan kondisi peserta didik saat ini.

Salah satu kompetensi guru yang perlu ditingkatkan adalah kemampuan mengelola pembelajaran, kompetensi ini berkaitan dengan kemampuan guru dalam pengelolaan pembelajaran di kelas yang meliputi: Perencanaan, Pelaksanaan dan Penilaian. Banyak dijumpai di lapangan kegagalan guru dalam melaksanakan pembelajaran di kelas disebabkan oleh program perencanaan pembelajaran yang belum maksimal, yakni Silabus dan RPP tidak disiapkan.

Perencanaan program berfungsi untuk memberikan arah pelaksanaan pembelajaran sehingga menjadi terarah dan efisien. Salah satu bagian dari perencanaan pembelajaran yang sangat penting dibuat oleh guru sebagai pengarah pembelajaran adalah silabus dan Rencana Pelaksanaan Pembelajaran (RPP). Silabus memberikan arah tentang apa saja yang harus dicapai guna menggapai tujuan pembelajaran dan cara seperti apa yang akan digunakan. Selain itu silabus juga memuat teknik penilaian seperti apa untuk menguji sejauh mana keberhasilan pembelajaran. Rencana Pelaksanaan Pembelajaran (RPP) adalah instrument perencanaan yang lebih spesifik dari silabus. Rencana Pelaksanaan Pembelajaran ini dibuat untuk memandu guru dalam mengajar agar tidak melebar jauh dari tujuan pembelajaran.

Dengan melihat pentingnya penyusunan perencanaan pembelajaran ini, guru semestinya tidak mengajar tanpa adanya rencana. Namun sayang perencanaan pembelajaran yang mestinya dapat diukur oleh kepala sekolah ini, tidak dapat diukur oleh kepala sekolah karena hanya direncanakan dalam pikiran sang guru saja. Akibatnya kepala sekolah sebagai pembuat kebijakan di sekolah tidak dapat mengevaluasi kinerja guru secara akademik. Kinerja yang dapat dilihat oleh kepala sekolah hanyalah kehadiran tatap muka, tanpa mengetahui apakah kemampuan guru dalam mengelola pembelajaran sudah sesuai dengan harapan atau belum, atau sudahkah kompetensi dasar yang harus dikuasai oleh siswa terkuasai dengan benar. 
Menurut Undang-undang No.14 tahun 2005 tentang Guru Dan Dosen pasal 10 ayat (1) kompetensi guru meliputi kompetensi pedagogik, kompetensi kepribadian, kompetensi sosial, dan kompetensi profesional yang diperoleh melalui pendidikan profesi. Salah satu kompetensi yang wajib dimiliki oleh seorang guru seperti diamanatkan dalam Peraturan pemerintah diatas adalah kompetensi pedagogik. Dalam Undang-undang No. 14 Tahun 2005 tentang Guru dan Dosen dikemukakan kompetensi pedagogik adalah "kemampuan mengelola pembelajaran peserta didik". Depdiknas (2004) menyebut kompetensi ini dengan "kompetensi pengelolaan pembelajaran. Kompetensi ini dapat dilihat dari kemampuan merencanakan program belajar mengajar, kemampuan melaksanakan interaksi atau mengelola proses belajar mengajar, dan kemampuan melakukan penilaian.

Seperti uraian diatas, unsur pertama dalam kompetensi pedagogik seorang guru adalah kemampuan merencanakan program belajar mengajar. Menurut Joni dalam Rusmiarsi (2017), kemampuan merencanakan program belajar mengajar mencakup kemampuan:

1) Merencanakan pengorganisasian bahan-bahan pengajaran,

2) Merencanakan pengelolaan kegiatan belajar mengajar,

3) Merencanakan pengelolaan kelas,

4) Merencanakan penggunaan media dan sumber pengajaran; dan

5) Merencanakan penilaian prestasi siswa untuk kepentingan pengajaran.

Setidaknya ada 7 aspek dalam kompetensi Pedagogik yang harus dikuasai, yaitu:

1) Karakteristik para peserta didik. Dari informasi mengenai karakteristik peserta didik, guru harus bisa menyesuaikan diri untuk membantu pembelajaran pada tiap-tiap peserta didik. Karakteristik yang perlu dilihat meliputi aspek intelektual, emosional, sosial, moral, fisik, dll.

2) Teori belajar dan prinsip pembelajaran yang mendidik. Guru harus bisa menerangkan teori pelajaran secara jelas pada peserta didik. Menggunakan pendekatan tertentu dengan menerapkan strategi, teknik atau metode yang kreatif.

3) Pengembangan kurikulum. Guru harus bisa menyusun silabus dan RPP sesuai dengan ketentuan dan kebutuhan. Mengembangkan kurikulum mengacu pada relevansi, efisiensi, efektivitas, kontinuitas, integritas, dan fleksibilitas.

4) Pembelajaran yang mendidik. Guru tidak sekedar menyampaikan materi pelajaran, namun juga melakukan pendampingan. Materi pelajaran dan sumber materi harus bisa dioptimalkan untuk mencapai tujuan tersebut.

5) Pengembangan potensi para peserta didik. Setiap peserta didik memiliki potensi yang berbeda-beda. Guru harus mampu menganalisis hal tersebut dan menerapkan metode pembelajaran yang sesuai, supaya setiap peserta didik bisa mengaktualisasikan potensinya.

6) Cara berkomunikasi. Sebagai guru harus bisa berkomunikasi dengan efektif saat menyampaikan pengajaran. Guru juga harus berkomunikasi dengan santun dan penuh empati pada peserta didik.

7) Penilaian dan evaluasi belajar. Penilaiannya meliputi hasil dan proses belajar. Dilakukan secara berkesinambungan. Evaluasi terhadap efektivitas pembelajaran juga harus bisa dilakukan..

Supervisi kepala sekolah merupakan upaya seorang kepala sekolah dalam pembinaan guru agar guru dapat meningkatkan kualitas mengajarnya dengan melalui langkah-langkah perencanaan, penampilan mengajar yang nyata serta mengadakan perubahan dengan cara yang rasional dalam usaha meningkatkan hasil belajar siswa. Supervisi yang dilakukan 
oleh kepala sekolah, tujuannya adalah membantu guru-guru memperbaiki situasi mengajar dan membantu guru dalam menganalisa kesulitan-kesulitan belajar dan kebutuhan siswa (Wahyuni, 2021; Suginam, 2019).

Salah satu tugas kepala sekolah adalah melaksanakan supervis akademik. Untuk melaksanakannya secara efektif, diperlukan keterampilan konseptual, interpersonal dan teknikal (Glickman, at al: 2007). Oleh sebab itu, setiap kepala sekolah harus memiliki keterampilan teknikal berupa kemampuan menerapkan teknik-teknik supervise akademik yang tepat. Menurut Gwyn dalam Sudiarti (2017) teknik supervisi akademik meliputi dua macam, yaitu: individual dan kelompok Teknik supervisi individual adalah pelaksanaan supervise persorangan terhadap guru. Supervisor hanya berhadapan dengan seorang guru sehingga dari hasil supervisi ini akan diketahui kualitas pembelajarannya.

Hasil pengamatan pada tahun pelajaran 2018/2019 di SMA Negeri 2 Pujut didapatkan data sebagai berikut: (1) Hanya 70\% guru yang menyusun silabus dan RPP sendiri. (2) Secara kualitas, silabus dan RPP yang baik baru mencapai angka 30\% dari silabus dan RPP yang dibuat oleh guru. Untuk mengatasi permasalahan tersebut, peneliti yang berkedudukan sebagai kepala sekolah di atas merencanakan untuk melakukan supervisi individual yang yang kontinyu. Dengan strategi ini diharapkan setelah kegiatan, guru yang menyusun silabus dan RPP meningkat. Adapun tujuan penelitian ini adalah untuk meningkatkan kemampuan mengelola pembelajaran guru mata pelajaran melalui supervisi individual yang kontinyu.

\section{Metode Penelitian}

Metode penelitian ini adalah penelitian tindakan sekolah, merupakan upaya yang dilakukan kepala sekolah untuk meningkatkan kualitas peran dan tanggung jawab guru khususnya dalam pengelolaan pembelajaran (Arikunto, 2009). Pelaksanaan penelitian ini pada tahun pelajaran 2018/2019 di SMA Negeri 2 Pujut, Lombok Tengah. Subjek dalam penelitian ini adalah 15 orang guru mata pelajaran yang ada di SMA Negeri 2 Pujut Lombok Tengah. Data yang diambil berupa dokumen Silabus dan RPP yang telah dibuat guru-guru mata pelajaran. Instrumen yang digunakan dalam penelitian ini meliputi lembar format silabus mata pelajaran, lembar format RPP mata pelajaran. Teknik analisis data dalam penelitian ini menggunakan uji persentase dengan analisis deskriptif kuantitatif.

$$
P=\frac{f}{N} \times 100 \%
$$

Dimana :

$$
\begin{array}{ll}
P & =\text { persentase yang dicari } \\
f & =\text { frekuensi siswa yang tuntas } \\
N & =\text { jumlah siswa keseluruhan }
\end{array}
$$

Peningkatan kemampuan mengelola pembelajaran individual akan ditentukan tercapai bila perolehan skor siswa mencapai nilai standar, yaitu 280 . Analisis data peningkatan kemampuan mengelola pembelajaran guru terhadap pembinaan dengan menggunakan model supervisi individualyang kontinyu dengan menggunakan tabel data. Kompetensi guru dikatakan baik apabila memperoleh hasil sekurang-kurangnya $80 \%$. Sebaliknya apabila hasil yang di peroleh di bawah $80 \%$ maka kompetensi guru dikatakan kurang atau tidak baik.

\section{Hasil Penelitian dan Pembahasan}

Hasil perolehan data penelitian pada SMA Negeri 2 Pujut Lombok Tengah tahun pelajaran 2019/2020 selama dua siklus dan pada setiap siklus diamati oleh peneliti dibantu wakasek. 


\section{Pra Siklus}

Mutu silabus dan mutu RPP yang dibuat guru SMA Negeri 2 Pujut pada umumnya dapat dikatakan kurang baik. Hal ini dikarenakan banyak silabus dan RPP menggunakan format yang lama dan hasil copy paste tida ada pengembangan. Hasil penilaian penulis terhadap kualitas silabus dan RPP 15 orang guru SMA Negeri 2 Pujut tahun pelajaran 2019/2020

Tabel 1. Daftar Nilai Mutu Silabus Dan Rpp Guru SMAN 2 Pujut

\begin{tabular}{|c|c|c|c|c|}
\hline No & $\begin{array}{c}\text { Kode Nama } \\
\text { Guru }\end{array}$ & Silabus & RPP & Rata-rata \\
\hline 1 & A & 76 & 80 & 78 \\
\hline 2 & B & 75 & 69 & 72 \\
\hline 3 & C & 62 & 70 & 66 \\
\hline 4 & D & 61 & 71 & 50 \\
\hline 5 & E & 73 & 75 & 71 \\
\hline 6 & F & 64 & 61 & 62 \\
\hline 7 & G & 64 & 61 & 62 \\
\hline 8 & H & 63 & 61 & 61 \\
\hline 9 & I & 64 & 61 & 62 \\
\hline 10 & J & 64 & 61 & 62 \\
\hline 11 & K & 62 & 61 & 61 \\
\hline 12 & L & 62 & 61 & 61 \\
\hline 13 & M & 62 & 61 & 61 \\
\hline 14 & N & 75 & 61 & 68 \\
\hline 15 & O & 75 & 75 & 76 \\
\hline Nilai tertinggi & $\mathbf{7 6}$ & $\mathbf{8 0}$ & $\mathbf{7 8}$ \\
\hline Nilai Terendah & $\mathbf{6 1}$ & $\mathbf{6 1}$ & $\mathbf{5 0}$ \\
\hline Rata-rata & $\mathbf{6 7}$ & $\mathbf{6 6}$ & $\mathbf{6 5}$ \\
\hline Jumlah $<70$ & $\mathbf{1 0}$ & $\mathbf{1 1}$ & $\mathbf{1 1}$ \\
\hline Jumlah $>70$ & $\mathbf{5}$ & $\mathbf{4}$ & $\mathbf{4}$ \\
\hline Prosentase $>70$ & $\mathbf{3 3}$ & $\mathbf{2 7}$ & $\mathbf{2 7}$ \\
\hline
\end{tabular}

\section{Deskripsi Siklus I}

Untuk siklus ini seluruh guru diminta untuk mengumpulkan perangkat pembelajaran tersebut. Selanjutnya peneliti melakukan analisis dan penilaian terhadap kuantitas guru yang menyetorkan perangkat pembelajaran terutama silabus dan RPP. Dari hasil perhitungan peneliti terhadap jumlah guru yang mengumpulkan silabus dan RPP didapatkan data sebagai berikut:

Tabel 2. Rekapitulasi Perhitungan Pengumpulan Silabus dan RPP pada Siklus 1

\begin{tabular}{|c|c|c|c|c|c|c|c|}
\hline \multirow{2}{*}{ No } & \multirow{2}{*}{ Kelas } & $\begin{array}{c}\text { Seharus } \\
\text { nya }\end{array}$ & $\begin{array}{c}\text { Mengumpul } \\
\text { kan }\end{array}$ & $\begin{array}{c}\% \\
\text { Mengumpul } \\
\text { kan }\end{array}$ & $\begin{array}{c}\text { Seharus } \\
\text { nya }\end{array}$ & $\begin{array}{c}\text { Mengumpul } \\
\text { kan }\end{array}$ & $\begin{array}{c}\% \\
\text { Mengumpul } \\
\text { kan }\end{array}$ \\
\hline 1 & $\mathrm{X}$ & 20 & 16 & 80 & 20 & 15 & 70 \\
\hline
\end{tabular}




\begin{tabular}{|c|l|l|l|l|l|l|l|}
\hline 2 & XI IPA & 18 & 15 & 83 & 18 & 14 & 72 \\
\hline 3 & XI IPS & 18 & 15 & 83 & 18 & 14 & 72 \\
\hline 4 & XII IPA & 18 & 15 & 83 & 18 & 14 & 72 \\
\hline 5 & XII IPS & 18 & 15 & 83 & 18 & 14 & 72 \\
\hline \multicolumn{2}{c|}{ Rata-rata } & & & $\mathbf{1 5}$ & $\mathbf{8 3}$ & $\mathbf{1 8}$ & $\mathbf{1 3}$ \\
\hline $\begin{array}{c}\text { Prosentase } \\
\text { Total }\end{array}$ & $\mathbf{7 8}$ & & \\
\hline
\end{tabular}

Dari data jumlah guru yang mengumpulkan silabus dan RPP pada awal siklus dapat terlihat bahwa dengan informasi adanya supervisi akademik terhadap guru dapat meningkatkan kuantitas jumlah guru yang menyusun silabus dan RPP yang sebelumnya hanya $64 \%$, mengalami peningkatan kuantitas menjadi $78 \%$.

Dari data tersebut juga dapat dilihat adanya guru yang hanya menyerahkan silabus tanpa dengan RPP-nya serta ada yang belum menyetorkan silabus dan RPP (Klasifikasi D).

\section{Kualitas silabus dan RPP setelah siklus ke-1}

Sebelum melakukan supervise individual terhadap seluruh guru terutama kepada guru yang belum menyetorkan silabus dan RPP. Peneliti melakukan analisa kedua terhadap sampel silabus dan RPP yang dibuat oleh guru. Hasil analisis kualitas silabus dan RPP tersebut dapat terlihat pada tabel berikut:

\section{Tabel 3. REKAPITULASI PENILAIAN SILABUS}

DAN RPP PADA SIKLUS 1

\begin{tabular}{|l|l|l|c|c|}
\hline No & Klasifikasi Penilaian & Rentang nilai & f & \% \\
\hline A. & SILABUS & & & \\
\hline 1 & A : Baik sekali & $86-100$ & - & - \\
\hline 2 & B : Baik & $71-85$ & 5 & 33 \\
\hline 3 & C : Cukup & $51-70$ & 10 & 67 \\
\hline 4 & D : Kurang & $0-50$ & - & - \\
\hline Jumlah & & $\mathbf{1 5}$ & $\mathbf{1 0 0}$ \\
\hline
\end{tabular}

\begin{tabular}{|l|l|l|c|c|}
\hline B. & RPP & & & \\
\hline 1 & A : Baik sekali & $86-100$ & - & - \\
\hline 2 & B : Baik & $71-85$ & 4 & 27 \\
\hline 3 & C : Cukup & $51-70$ & 11 & 73 \\
\hline 4 & D : Kurang & $0-50$ & - & \\
\hline Jumlah & $\mathbf{1 5}$ & 100 \\
\hline
\end{tabular}

\section{Deskripsi Siklus II.}

Sementara itu, hasil analisa kualitas penyusunan silabus dan RPP setelah dilakukan supervis individual (setelah direvisi) dapat dilihat pada table berikut:

Tabel 4. REKAPITULASI PENILAIAN SILABUS

DAN RPP SETELAH REVISI

\begin{tabular}{|l|l|l|c|c|}
\hline No & Klasifikasi Penilaian & Rentang nilai & f & \% \\
\hline A. & SILABUS & & & \\
\hline 1 & A : Baik sekali & $86-100$ & 3 & 20 \\
\hline
\end{tabular}




\begin{tabular}{|l|l|l|c|c|}
\hline 2 & B : Baik & $71-85$ & 12 & 80 \\
\hline 3 & C : Cukup & $51-70$ & - & - \\
\hline 4 & D : Kurang & $0-50$ & & \\
\hline \multicolumn{2}{|l|}{ Jumlah } & & 15 & 100 \\
\hline
\end{tabular}

\begin{tabular}{|l|l|l|c|c|}
\hline B. & RPP & & & \\
\hline 1 & A : Baik sekali & $86-100$ & 2 & 11 \\
\hline 2 & B : Baik & $71-85$ & 13 & 87 \\
\hline 3 & C : Cukup & $51-70$ & & \\
\hline 4 & D : Kurang & $0-50$ & - & - \\
\hline \hline \multicolumn{2}{|l|}{ Jumlah } & & 15 & 100 \\
\hline
\end{tabular}

Hasil analisa revisi silabus dan RPP pada tabel diatas memperlihatkan terjadinya peningkatan kualitas silabus dan RPP. Dimana kualitas A dan B meningkat dari 67 dan 80\% menjadi 73 dan $87 \%$. Dari sini pula terlihat bahwa jumlah guru yang mengumpulkan sampel silabus dan RPP menjadi $100 \%$.

\section{Kompetensi guru menyusun silabus dan RPP setelah siklus ke-2}

Pada siklus kedua ini, penelitian dilanjutkan dengan menganalisa/menguji keaslian silabus dan RPP yang disusun oleh guru. Metode yang digunakan adalah dengan melakukan supervise kelas. Dari pelaksanaan rencana pembelajaran ini, dapat terlihat keaslian penyusunannya. Hasil dari analisa penguat tersebut, menunjukkan bahwa silabus dan RPP yang dikumpulkan benar disusun oleh guru yang bersangkutan. Karena terjadi kesesuaian scenario antara perencanaan dan pelaksanaan di kelas. Data kesesuaian tersebut dapat dilihat dari table berikut:

Tabel 5. HASIL PENILAIAN SUPERVISI KELAS

\begin{tabular}{|l|l|c|c|c|}
\hline No & \multicolumn{1}{|c|}{$\begin{array}{c}\text { Klasifikasi } \\
\text { Penilaian }\end{array}$} & Rentang nilai & f & \% \\
\hline 1 & A : Sesuai & $76-100$ & 12 & 84 \\
\hline 2 & B : Cukup sesuai & $51-75$ & 3 & 16 \\
\hline 3 & C : Kurang sesuai & $26-50$ & - & - \\
\hline 4 & D : Tidak sesuai & $0-25$ & - & - \\
\hline Jumlah & 15 & 100 \\
\hline
\end{tabular}

\section{Kesimpulan}

Dari hasil penelitian ini dapat disimpulkan bahwa pada penelitian tindakan kelas yang telah dilaksanakan selama 2 siklus terjadi peningkatan jumlah silabus guru yang baik dari 33\% menjadi $80 \%$ setelah supervisi individual. Selain itu jumlah RPP yang berkualitas baik juga meningkat dari $27 \%$ menjadi $87 \%$. Peningkatan kompetensi guru dalam menyusun silabus dan RPP yang baik meningkat sebesar $80 \%$ dan $87 \%$.

\section{Saran}

Adapun saran berdasarkan hasil penelitian ini adalag agar guru dapat secara konsisten meningkatkan kualitas pembelajarannya melalui penerapan metode pembelajaran yang 
inovatif dan kreatif. Disamping itu Kepala Sekolah juga agar tetap secara berkelanjutan melakukan supervise akademik.

\section{Daftar Pustaka}

Arikunto, Suharsimi. (2009). Penelitian Tindakan Kelas. Jakarta: Bumi Aksara.

Depdiknas. (2004). Supervisi Akademik; Materi Pelatihan

Islamuddin, I. (2021). Supervisi Klinik sebagai Upaya Meningkatkan Kemampuan Guru dalam Mengelola Pembelajaran di SMA Negeri 8 Gowa. Jurnal Paedagogy, 8(4), 482-489. doi:https://doi.org/10.33394/jp.v8i4.4013

Majid, Abdul. (2005). Perencanaan Pembelajaran: Mengembangkan Standar Kompetensi Guru. Bandung: PT Remaja Rosdakarya.

Mulyasa, Enco. (2012). Menjadi Guru Profesional Menciptakan Pembelajaran Kreatif dan Menyenangkan. Bandung: PT Remaja Rosda Karya.

Rusmiarsi, R. (2017). Meningkatkan Kompetensi Guru dalam Proses Pembelajaran Berdasarkan Kurikulum 2013 Melalui Supervisi Akademik di SD Negeri 40 Ampenan. Jurnal Kependidikan: Jurnal Hasil Penelitian dan Kajian Kepustakaan di Bidang Pendidikan, Pengajaran dan Pembelajaran, 3(2). doi:https://doi.org/10.33394/jk.v3i2.680

Sagala, Syaiful. (2011). Konsep dan Makna Pembelajaran untuk Membantu Memecahkan Problematika Belajar dan Mengajar. Bandung: Alfabeta

Sapari, Achmad. (2002). Pemahaman Guru Terhadap Inovasi Pendidikan. Artikel. Jakarta: Kompas (16 Agustus 2002).

Sudiarti, D. (2017). Upaya Meningkatkan Kompetensi Guru Kelas dalam Proses Pembelajaran Melalui Supervisi Akademik di SDN 9 Cakranegara. Jurnal Kependidikan: Jurnal Hasil Penelitian dan Kajian Kepustakaan di Bidang Pendidikan, Pengajaran dan Pembelajaran, 3(1). doi:https://doi.org/10.33394/jk.v3i1.463

Suginam, A. (2019). Upaya Meningkatkan Kompetensi Guru Kelas dalam Proses Pembelajaran Melalui Supervisi Akademik di SD Negeri 4 Mataram. Jurnal Paedagogy, 6(2), 41-48. doi:https://doi.org/10.33394/jp.v6i2.2530

Supatni, P. (2017). Mengefektifkan Pelaksanaan Supervisi Akademik dalam Upaya Meningkatkan Kompetensi Guru Kelas dalam Proses Pembelajaran di SDN 36 Ampenan. Jurnal Kependidikan: Jurnal Hasil Penelitian dan Kajian Kepustakaan di Bidang Pendidikan, Pengajaran dan Pembelajaran, 3(1). doi:https://doi.org/10.33394/jk.v3i1.473

Wahyuni, T. (2021). Supervisi Klinis oleh Kepala Sekolah guna Meningkatkan Kompetensi Guru dalam Mengelola Administrasi Kelas di SD Negeri 42 Ampenan. Jurnal Paedagogy, 8(2), 264-270. doi:https://doi.org/10.33394/jp.v8i2.3561

Wardani, IGAK. (2007). Pemantapan Kemampuan Profesional. Jakarta: Universitas Terbuka. 